This is a post-print. Published version at https://doi.org/10.1108/DLP-11-2017-0043

\title{
Distributed Digital Preservation: Preserving Open Journal Systems Content in the PKP PN
}

\begin{tabular}{|c|c|}
\hline Journal: & Digital Library Perspectives \\
\hline Manuscript ID & DLP-11-2017-0043.R1 \\
\hline Manuscript Type: & Case Study \\
\hline Keywords: & $\begin{array}{l}\text { digital preservation, open source software, partnerships, Open Journal } \\
\text { Systems (OJS), open access journals, Private LOCKSS Network (PLN) }\end{array}$ \\
\hline \multicolumn{2}{|c|}{$\begin{array}{l}\text { Bronwen Sprout, University of British Columbia, Vancouver, Canada and Mark Jordan, Simon Fraser University, } \\
\text { Vancouver, Canada }\end{array}$} \\
\hline
\end{tabular}

\section{SCHOLARONE ${ }^{\text {m }}$ \\ Manuscripts}




\section{Introduction}

In June 2016 the Public Knowledge Project (PKP) announced the launch of a Preservation Network (PN) to digitally preserve journals that publish using the Open Journal Systems (OJS) software. The vast majority of the estimated 10,000+ journals published using OJS are not preserved by a recognized digital preservation service. The PKP PN meets this need, providing free preservation services by collecting article content from any eligible OJS journal and preserving it in a network of (at the time of writing) eight "preservation nodes" based on the LOCKSS system. After a trigger event -- when the original journal is no longer accessible permanently -- the content will be made publicly available in one or more "access nodes" running OJS.

The PKP PN, which is a free service provided by PKP and its partners, was launched in June 2016 and nearly 18 months later, almost 600 journals are being preserved in this worldwide preservation network (joining at the rate of about one per day). While this adoption is not insignificant, it represents only a small portion of OJS journals, many of which are open access and published by small publishers, and at particular risk of loss. Factors such as OJS user interface and workflow design as well as awareness of the service and of preservation risks all play a part in journal participation in the network. The authors discuss the challenges encountered in developing the PN as well as strategies for increasing participation.

\section{Context for the PKP Preservation Network}

The Public Knowledge Project (PKP) is a multi-university initiative based at Simon Fraser University in Vancouver, British Columbia, which develops free open source software and conducts research to improve the quality and reach of scholarly publishing. It is perhaps best known for developing the OJS software, which was launched in 2002 and is now the world's most widely used journal management and publishing system, made freely available worldwide for the purpose of making open access, peer-reviewed publishing a viable option for more journals ${ }^{1}$. PKP was established in 1998 by John Willinsky, then at the University of British Columbia, and now at Stanford University. The central objective of PKP since that time continues to be "improv[ing] both the scholarly quality and public access to the body of research knowledge in a sustainable and globally accessible form" (Owen and Stranack, 2012, 138). In support of this objective, PKP invests in ongoing work to improve the software it develops - in addition to OJS, this includes Open Conference Systems and Open Monograph Press - and to contribute to enhancing the technology for scholarly communication.

Testament to its popularity, the number of OJS journals has grown steeply since the initial release of this software, especially over the last 10 years. In 2016, more than 10,000 journals published more than 400,000 articles using OJS, with the highest concentration of usage in Latin America and the Caribbean, followed by East and Central Asia and Europe ${ }^{2}$.

Figure 1: OJS usage over time

\footnotetext{
${ }^{1}$ https://pkp.sfu.ca/ojs/

${ }^{2}$ Using the criteria of "at least 10 articles published that year" https://pkp.sfu.ca/ojs/ojs-usage/ojs-stats/
} 
Using only the simple metric of the volume of scholarly content being produced and managed in OJS journals, their preservation status is worthy of concern. However, further data, based on a survey conducted by PKP in 2009, suggests that OJS journals are particularly vulnerable to loss. The results of this survey showed that OJS journals are primarily born digital, published by independent or scholarly publishers, and predominantly open access. It also showed that they are operating on a budget, without the resources available to commercial publishers (Edgar and Willinsky, 2010). Among the use cases for ejournal preservation identified by Neal Beagrie in a 2013 DPC Technology Watch Report, two are particularly applicable to these journals: if the publisher ceases operating or their operations or servers suffer catastrophic failure, this content would likely disappear (2013). As Seadle explains, "[f]ew librarians serious expect a large publisher like Elsevier or Springer to vanish overnight, but the danger for a publisher with only one or even fewer than ten titles is historically much larger $(2011,194)$ ".

Prior to the launch of the PKP PN, the available distributed preservation options were not practical for most OJS journals. The major, well-established ejournal preservation services LOCKSS, CLOCKSS and Portico - are not a good fit due to cost, membership requirements or content restrictions. LOCKSS (Lots of Copies Keeps Stuff Safe) is an open source, library-led digital preservation system that was developed and is based at Stanford University. The primary implementation of this software is the Global LOCKSS Network (or GLN) which preserves mainly subscription-based journal content. Publishers participate in the GLN at no cost, which would seem to align this preservation option with OJS journals. However, at the time of writing, the GLN preserves content from around 200 OJS titles (out of approximately 10,000). This is in large part because OJS journals are generally not a top preservation priority for LOCKSS Alliance libraries who vote on the content that is preserved in the $\mathrm{GLN}^{3}$. And because OJS journals tend to be published by many different publishers in relatively small numbers, there is also an issue of economies of scale in working with publishers.

Private LOCKSS Networks (PLNs) like the PKP PN are used to preserve content in specialized areas; a small number of PLNs other than PKP's preserve OJS journals hosted by their member

\footnotetext{
${ }^{3}$ https://www.lockss.org/support/prepare-your-content/open-access-preservation-options/
} 
libraries. However, these PLNs have membership requirements as well as associated membership fees, restricting access to a minority of OJS titles (Skinner and Schultz, 2010). Other established preservation services including Controlled LOCKSS (CLOCKSS) and Portico also have associated membership fees for publishers which, while relatively small for journals with lower revenue, are out of reach for many OJS journals.

While the preservation problem is particularly acute for OJS journals, two separate studies have found that only around one quarter of all ejournal titles with ISSNs currently collected have been preserved by a recognized archiving program (Burnhill and Otty, 2015; Cornell University Library \& Columbia University Library LOCKSS Assessment team, 2011). The Keepers Registry, which maintains metadata recording ejournal archiving arrangements, suggest that this means "about three-quarters of titles (with ISSNs) could be said to be at risk" (Burnhill, 2013, 6). Additionally, the Mellon-funded Strategies for Expanding Ejournal Preservation study at Cornell University Library \& Columbia University Library found that there was not much overlap between the content preserved by the various initiatives like Portico and LOCKSS. At the time of their analysis, "Cornell held 45,602 e-journal titles with an ISSN, elSSN, or both....Of the 45,602, both LOCKSS and Portico preserve 3,476 or 7.6\%" (Cornell University Library \& Columbia University Library LOCKSS Assessment team, 2011,15). ${ }^{4}$

This problem is even greater for Open Access journals, the category that the vast majority of OJS titles fall into. A 2013 survey by the Directory of Open Access Journals (DOAJ) underscores how significant a problem is the preservation of open access journals more generally. In keeping with survey data collected by PKP about OJS journals, the DOAJ data shows that there are a few open access publishers indexed in DOAJ with more than 50 journals, but thousands publishing one or two journals, many of which lack the resources to go beyond publishing the content, and most that had not addressed the issue of journal preservation (Bjornshauge, 2014). Indeed, based on their analysis of Keepers Registry data, Burnhill and Otty conclude that "the journals from smaller publishers - those in the so-called 'long tail' -are less likely to be ingested by organisations with archival intent, and are therefore at much greater risk of loss. Ensuring that this part of the scholarly record is kept safe is perhaps the most difficult task facing the library community" (Burnhill and Otty, 2015, 5). These findings highlight the need for additional and complementary options for preservation of electronic journals, in particular for open access journals.

These gaps in the ejournal preservation landscape combined with a few other factors to prompt PKP to develop the PKP PN as part of its service offerings. Firstly, PKP is starting to develop coordinated services for the OJS community, and preservation efforts are consistent with that focus (its other services include aggregating OJS journals into a central index, article-level metrics, and DOI integration). As well, several PKP Development partners are members of the LOCKSS Alliance, so adding a LOCKSS box for the PKP PN would be a familiar technology and would not come with an additional cost for these members. A PLN for OJS journals is consistent with LOCKSS' "community" focus whereby "like-minded institutions work together to share the preservation responsibility (including governance and sustainability) of e-content important to

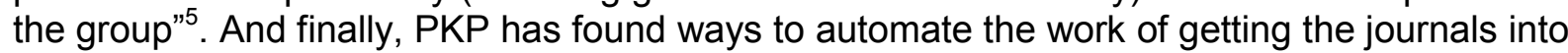
the $\mathrm{PN}$, meaning that the service is not time-intensive to maintain once launched, and that staffing costs are kept to a minimum.

\footnotetext{
${ }^{4}$ Seadle, on the other hand, in a separate analysis of LOCKSS, CLOCKSS and Portico data, found "significant overlap among the archiving systems" though he notes that "[p]art of the overlap comes from a few large publishers, who use both systems" (2011).

${ }^{5}$ https://www.lockss.org/community/networks/
} 
One of PKP's goals in developing the PN was to maintain a low barrier to entry in order to enable as much participation as possible. The resulting network provides free preservation services for any OJS journal that meets a few minimum requirements. At the time of writing, these requirements are that the journal has published at least one article, has an ISSN and is running a current version of OJS. The PN allows OJS journal managers to register their journals for inclusion in the PN by enabling a plugin in their OJS instance and agreeing to the terms of a preservation agreement. On registration of a journal, the PN automatically determines if the registered journal meets the minimum inclusion requirements, prepares the raw journal content generated by OJS's existing export tools, harvests new content from registered journals, and adds the content to the PN, thus eliminating manual staff intervention at PN member sites and centrally at PKP.

The PKP PN, like most Private LOCKSS Networks, is a dark archive, meaning that end users will not have access to the preserved content until after a "trigger event" (Reich and Rosenthal, 2009). In the PKP PN's case, the trigger event can be notification by the journal manager or cessation of deposits into the PN after a period of inactivity. If a potential trigger event is detected, PKP staff will contact the journal to confirm its publication status and if it is confirmed, approve the importing of preserved content into a special OJS instance — an "access node" operated by the PN where it will be openly accessible.

As Kenney asserts, the shift from print to electronic journals has brought a number of causes for concern related to preservation, not least of which is that the "well-defined relationships and roles of the print era continue into the digital era and are inhibiting collaborative approaches to solving these problems today" (Kenney and Wesley, 2016). Kenney calls on libraries, publishers, and preservation repositories to develop cooperative approaches to ejournal preservation. The PKP PN is representative of an approach that involves cooperation by all of these parties.

\section{Terms of Service}

Journal managers who would like their journal to be included in the PKP PN must accept the terms of service in the OJS plugin. This agreement currently consists of eight clauses:

1. I have the authority to include this journal's content in a secure preservation network and, if and when necessary, to make the content accessible in the PKP PN and its successors.

2. I agree to allow the PKP PN to include this journal's title and ISSN, and the email address of the Primary Contact, with the preserved journal content.

3. I confirm that licensing information pertaining to articles in this journal is accurate at the time of publication.

4. I acknowledge these terms may be revised from time to time and will supersede all previous versions. I will be asked to review them and to agree to them in order to continue to include this journal's content in the PKP PN.

5. I agree not to violate any laws and regulations that may be applicable to the content.

6. I agree to make every reasonable effort to inform the PKP PN in the event this journal ceases publication. I acknowledge that the PKP PN will also employ automated 
techniques to detect a potential trigger event and contact the journal to confirm their publication status.

7. I agree that the PKP PN reserves the right not to preserve or make content accessible.

8. PKP reserves the right to use the aggregated content in the PKP PN for research and reporting purposes and will adhere to the norms of standard research procedures.

Development of the terms was an iterative process driven by several principles related both philosophically and technically to the planned PN, namely: ingesting journal content must be completely automated from the journal's point of view, and as automated as possible from PKP's point of view (i.e. until such a point as manual intervention is necessary in deciding whether to make content available after a trigger event); joining the PN must be as simple as possible for journals managers, and getting content out of the PN for distribution after a trigger event must be as simple as possible for PKP staff; making content available after a trigger event must be as future proof as possible; that is, policies and processes must save effort for the people in the future who will retrieve content and make it available; and finally, the PN should be inclusive.

A number of methods were used to test the first and subsequent draft service agreements. Besides inviting several OJS journals to participate in early testing, the authors held a workshop focused on the terms at the 2015 PKP conference; this workshop was attended by OJS journal managers from around the world. PKP also received advice from lawyers based in Canada and the United States and from the PKP PN Advisory Panel ${ }^{6}$.

Early testing quickly identified a number of issues with a planned CC-BY ${ }^{7}$ license stipulation: some journals were using other variations of Creative Commons (CC) licenses, others had changed licenses and intellectual property arrangements as they moved from toll to open access, and yet others had concerns about accepting an explicit CC license without consulting all affected authors (a daunting task for those journals which had been publishing for many years). Based on this feedback, the CC-related clause was removed from the terms as was language around post-trigger event scenarios that might have legal significance.

In a literature review and survey conducted between 2002 - 2004, Ayre and Muir identified a number of complicated rights issues and solutions associated with digital preservation including copyright legislation related to preservation copying and the ability for publishers to grant permission to preserve materials that have multiple rights holders (2004). In the intervening fifteen years, new issues and approaches to rights management in the digital environment such as CC licenses - have arisen. These issues, along with content licenses, copyright and intellectual property laws, will inevitably continue to evolve; highly specific and legally binding

\footnotetext{
${ }^{6}$ At the time of writing, the PKP PN Advisory Panel was comprised of: Lars Bjornshauge, Directory of Open Access Journals (DOAJ), Sioux Cumming, International Network for the Availability of Scientific Publications (INASP), Alan Darnell, Ontario Council of University Libraries (OCUL), Geoff Harder, University of Alberta Libraries, Alex Mendonça, SciELO, Susan Murray, African Journals Online (AJOL), Victoria Reich, LOCKSS, Heather Joseph, SPARC, Dwayne K. Buttler, J.D., University of Louisville ${ }^{7}$ https://creativecommons.org/licenses/by/4.0/
} 
terms may prove out of sync with long term preservation goals. Further, at least for the PKP PN, the risk related to making post-trigger event content accessible is very low, regardless of the original license under which the content may have been published. The community that is served by the PKP PN is, for the most part, making content available under an open access license or model and is interested in the accessibility and persistence of their content. In the unlikely event that someone takes issue with content that has been made accessible, the simple recourse will be to take it down immediately. On a related note, the terms do not include dispute resolution clauses: the PKP PN is a collaborative and mutual network arrangement and "dispute resolution and other harshly binary clauses can abrogate any meaningful notion of a trust foundation for operating in collaborative ways" (Dwayne Buttler, personal email to author, July $27,2016)$.

As work on the service agreement evolved, additional principles solidified: the terms should be as simple and "plain language" as possible so they could be easily understood by a global audience (and lend themselves to translation where necessary); the onus should be on individual journals to confirm they are both willing and able to participate in the PN; the terms should be jurisdiction-neutral; and they should minimize risk to the PKP partners and sponsors who are active participants in the PKP PN. Though development of the terms proved one of the more challenging aspects of launching the PN, identifying key principles and testing the terms with OJS users ensured that the resulting agreement is consistent with the technical and philosophical vision for the PN.

\section{The PKP PN's User Interface and Network Architecture}

From a journal manager's perspective, the terms of service for the PKP PN are the main user interface to the network. Once the journal manager accepts the terms via a simple form within plugin's web interface, all of the journal's published issues are deposited into the network automatically, and each new issue is deposited on publication. The network is innovative in this respect; in most Private LOCKSS Networks, adding new content is a manual process (although some PLNs have developed various ways of making that task as simple as possible).

Because the addition of new OJS issues to the PN is automated, and because new journals join the network on a daily basis, PKP had to develop a network architecture and associated tools that would isolate the preservation nodes on the network (which are conventional LOCKSS servers) from the OJS instances, and that would also check the content produced by the OJS instances for potential threats such as viruses and spoofed content intended to overload the network. To do this, PKP inserted a staging server between the OJS journals and the LOCKSS network. The PKP PN plugin for OJS communicates directory with the staging server, and the staging server then communicates with the LOCKSS network. The lifecycle of a deposit is:

1. On publication of the issue, the journal sends a message to the staging server informing it of the new issue. 
2. The staging server retrieves the issue content from the OJS instance, and runs some validation checks (including a virus check) against the content.

3. The staging server then packages up the content in the form that will be preserved in the LOCKSS network and informs the preservation nodes that new content is available.

4. Finally, the preservation nodes harvest the content from the staging server and add it to the dark archive.

If PKP staff recognize a trigger event, they will extract the journal's content from the dark archive and load it into the access node described earlier.

At the time of writing, the preservation nodes in the PKP PN are hosted at Indiana University, the Italian National Library of Florence, the National Documentation Centre in Greece, the Ontario Council of University Libraries (Scholars Portal), Simon Fraser University, University of Alberta, University of British Columbia, University of Pittsburgh, and the University of Victoria. ${ }^{8}$ Whereas journals that register with the PKP PN simply submit a form containing the terms of use as described above, institutions that maintain preservation nodes agree to a Memorandum of Understanding that defines the relationships between PKP and the host institutions, and the obligations of each party. The Memorandum also outlines contractual or legal issues that host institutions (such as universities) require. However, consistent with the terms of use that journal managers accept, the preservation nodes' Memorandum is intended to be simple, clear, and as free of jurisdictional specifics as possible.

\section{Discussion and Future Work}

\section{Current Usage of the PN}

The PKP PN officially launched in June 2016 when notifications were sent to a number of relevant listservs and details about the availability of the PN were added to PKP's website. Nearly eighteen months later, as of November, 2017, more than 600 OJS journals have agreed to the terms of service and the response from the OJS and preservation communities has been overwhelmingly positive. Journals from 37 countries have joined the PN.

Table 1: Geographic distribution of journals in the PKP $\mathrm{PN}^{9}$

\begin{tabular}{|l|l|}
\hline Country & Number of journals \\
\hline United States & 152 \\
\hline Canada & 91 \\
\hline
\end{tabular}

\footnotetext{
${ }^{8}$ A preservation node is a server running the LOCKSS software.

${ }^{9}$ Only countries that have 5 or more journals in the PKP PN are included in this table; not shown are 20 countries that have fewer than 5 journals in the PN.
} 


\begin{tabular}{|l|l|}
\hline Brazil & 84 \\
\hline Italy & 74 \\
\hline Indonesia & 37 \\
\hline Costa Rica & 34 \\
\hline Ireland & 23 \\
\hline Argentina & 17 \\
\hline Germany & 15 \\
\hline Russia & 12 \\
\hline United Kingdom & 9 \\
\hline Singapore & 8 \\
\hline Norway & 8 \\
\hline France & 7 \\
\hline Turkey & 6 \\
\hline Malaysia & 5 \\
\hline Cuba & 5 \\
\hline
\end{tabular}

PKP worked with the LOCKSS team at Stanford to plan and launch the PN, and with the Directory of Open Access Journals (DOAJ) to ensure that the PKP PN meets its criteria to be one of the resources that is explicitly mentioned as a preservation service in the DOAJ application. This development with DOAJ was made possible by the PKP PN's acceptance in the Keepers' Registry, which enables PKP to publicly share information on its archived titles. The Keepers Registry "acts as a global monitor on the archiving arrangements for electronic journal," providing information about which journals are preserved by which archiving services and highlighting those journals for which no arrangements exist. ${ }^{10}$ DOAJ checks the Registry to confirm that a journal's archiving arrangements are as stated in its application. Thus, the PKP PN should have positive implications for the OJS-based journals which apply for inclusion in DOAJ, as well as those that wish to qualify for the DOAJ Seal (journals that are awarded the Seal are those that adhere to outstanding best practice ${ }^{11}$ ). Since 2014 when DOAJ expanded its review criteria and process, verifying a journal's digital archiving practices is one method that DOAJ uses to ensure the journals it indexes are of a high quality; recent analysis by Marchitelli et al. confirms this approach (Marchitelli et al, 2017).

\footnotetext{
${ }^{10} \mathrm{https}$ ://thekeepers.org

${ }^{11} \mathrm{https}$ ://doaj.org/faq\#seal
} 
Despite the positive response to the PKP PN's launch, the approximately 600 journals currently preserving content in the PKP PN is a fraction of the OJS journals that are eligible to do so. Using a script, the authors attempted to determine how many journals from the list used to compile the OJS usage statistics in Figure 1 met the PN's minimum requirements: 1) that they be running a version of OJS at least as recent as OJS 2.4.8 and 2) that they have an ISSN. Of the approximately 10,000 journals, more than 2,500 met both requirements.

\section{Improving the User Interface}

Considering that the PN is a free service, technical and communication factors both likely play a role in this delayed takeup. Because the service relies on a plugin, it is currently only available for a specific release of the OJS software. Work is underway so that the plugin will be available for the most current version of OJS, but users who have not yet upgraded to the 2.4.8 version of OJS will not have access to the service. Further, in OJS 2.4.8, the location of the PKP PN plugin is not obvious; given its longer association with OJS, a pre-existing LOCKSS plugin is more prominent. This challenge is being addressed in part by making the $\mathrm{PN}$ more prominent in the interface for OJS 3.1. (Because OJS downloads are not tracked or registered, PKP has no method of knowing or contacting all OJS users, or all OJS hosts, to notify them of the availability of new services like the PKP PN.)

Users must opt into the PKP PN by means of enabling a plugin in OJS. In the OJS 2.4.8 interface, plugins are grouped together in the "journal management" area, and appear as an item on a list of "management pages" called "system plugins". Clicking on "system plugins" brings the user to a "plugin management" page (Figure 2); the PKP PN plugin is part of a group of plugins called "generic plugins" (Figure 3), located partway down this list. Though the pathway to the PKP PN plugin is documented, it is not intuitive; users must know the plugin exists and purposefully navigate to that page to enable it.

Figure 2: OJS 2.4.8 Plugin Management

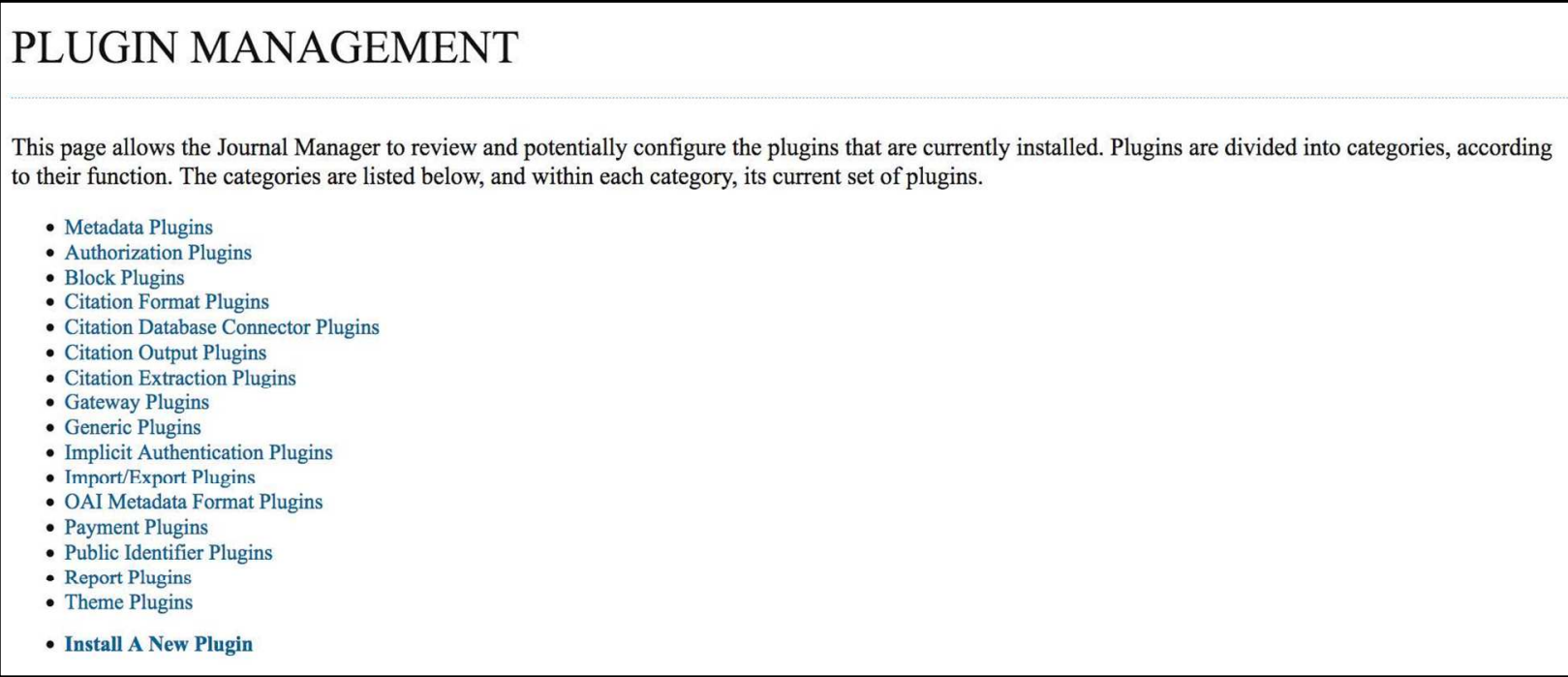


Figure 3: OJS 2.4.8 Generic Plugins (partial list)

\section{- ANNOUNCEMENT FEED PLUGIN \\ This plugin produces RSS/Atom web syndication feeds for journal announcements.}

ENABLE UPGRADE PLUGIN DELETE PLUGIN

\section{- STATIC PAGES PLUGIN}

This plugin allows Static Content Management.

ENABLE UPGRADE PLUGIN DELETE PLUGIN

\section{- BACKUP PLUGIN}

This plugin generates a backup of the installation.

ENABLE UPGRADE PLUGIN DELETE PLUGIN

- DRIVER

The DRIVER plugin extends the OAI-PMH interface according to the DRIVER Guidelines 2.0, helping OJS journals to become DRIVER compliant. ENABLE UPGIKADE PLUGIN DELEIE PLUGIN

\section{- PKP PLN PLUGIN}

The PKP PLN plugin will deposit your published content into the PKP Private LOCKSS Network for preservation. ENABLE UPGRADE PLUGIN DELETE PLUGIN

\section{- DATAVERSE PLUGIN}

Deposit data sets and/or other supplementary files to a Dataverse.

ENABLE UPGRADE PLUGIN DELETE PLUGIN

In contrast to the hidden location of the option for enabling the PKP PN plugin, enabling general LOCKSS harvesting for inclusion in the Global LOCKSS Network and conventional PLNs in OJS 2.4.8 is relatively obvious. The option is included in the "Policies" settings within the "Journal Setup" section, along with the peer review and privacy options:

\section{Figure 4: OJS 2.4.8 Journal Archiving options}

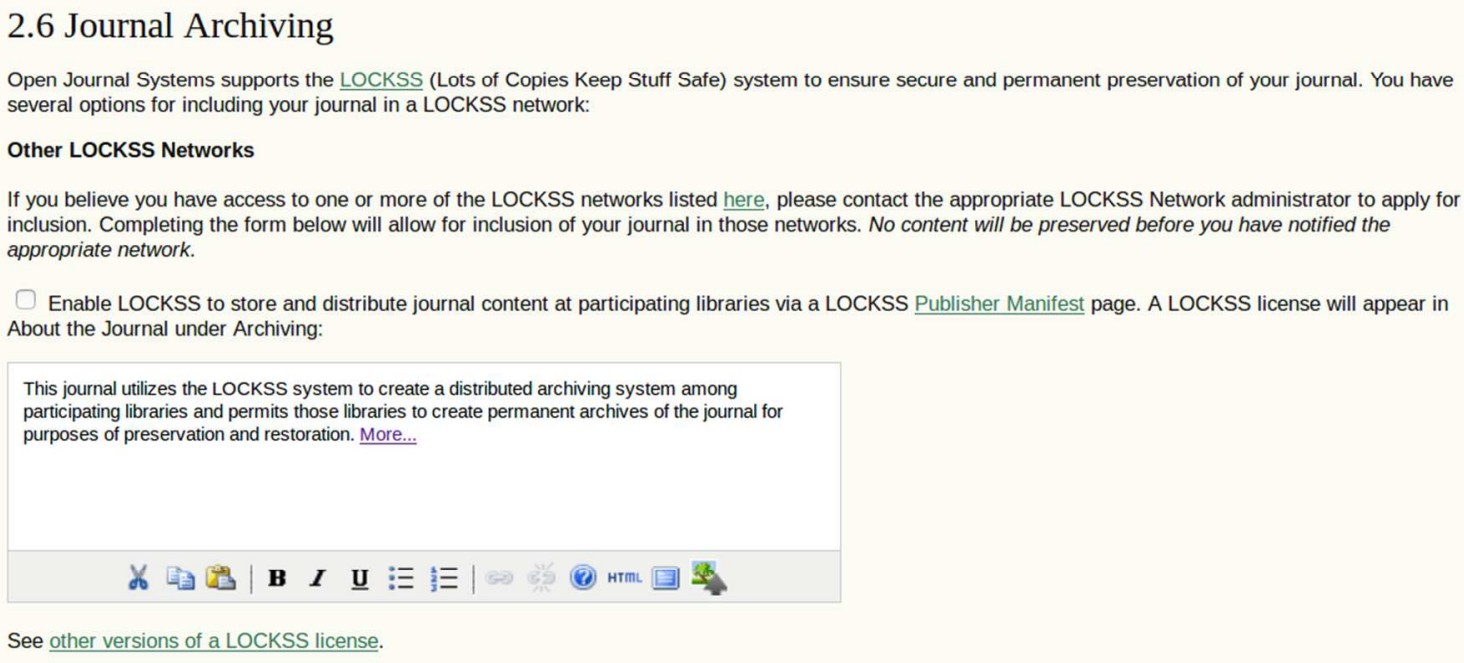

In OJS 2.4. 8, "Enabl[ing] LOCKSS to store and distribute journal content" (as in Figure 4) is much easier than enabling the PKP PN plugin. This ease is substantiated by the number of journals that have enabled the LOCKSS option. Running another script against the list of 
journals used to compile the OJS usage statistics in Figure 1, the authors attempted to determine how many journals enabled this option by requesting each journal's LOCKSS permission statement. They found that approximately one third of the journals tested provided a LOCKSS permission statement. In contrast, the total number of OJS journals archived in the Global LOCKSS Network is around 200. ${ }^{12}$ The authors speculate that the relatively high visibility of this configuration option, plus the brand recognition of "LOCKSS" as preservation platform, account for the roughly 3,000 journals that have enabled this option without belonging to a LOCKSS network ${ }^{13}$.

The PKP PN plugin was not included in OJS 3.0 as the plugin required upgrades that were not in place for the release date. As seen in Figure 5 though, an "Archiving" tab was introduced to the interface in this major release, as part of a group of "website settings."

\section{Figure 5: OJS 3.0 Archiving tab}

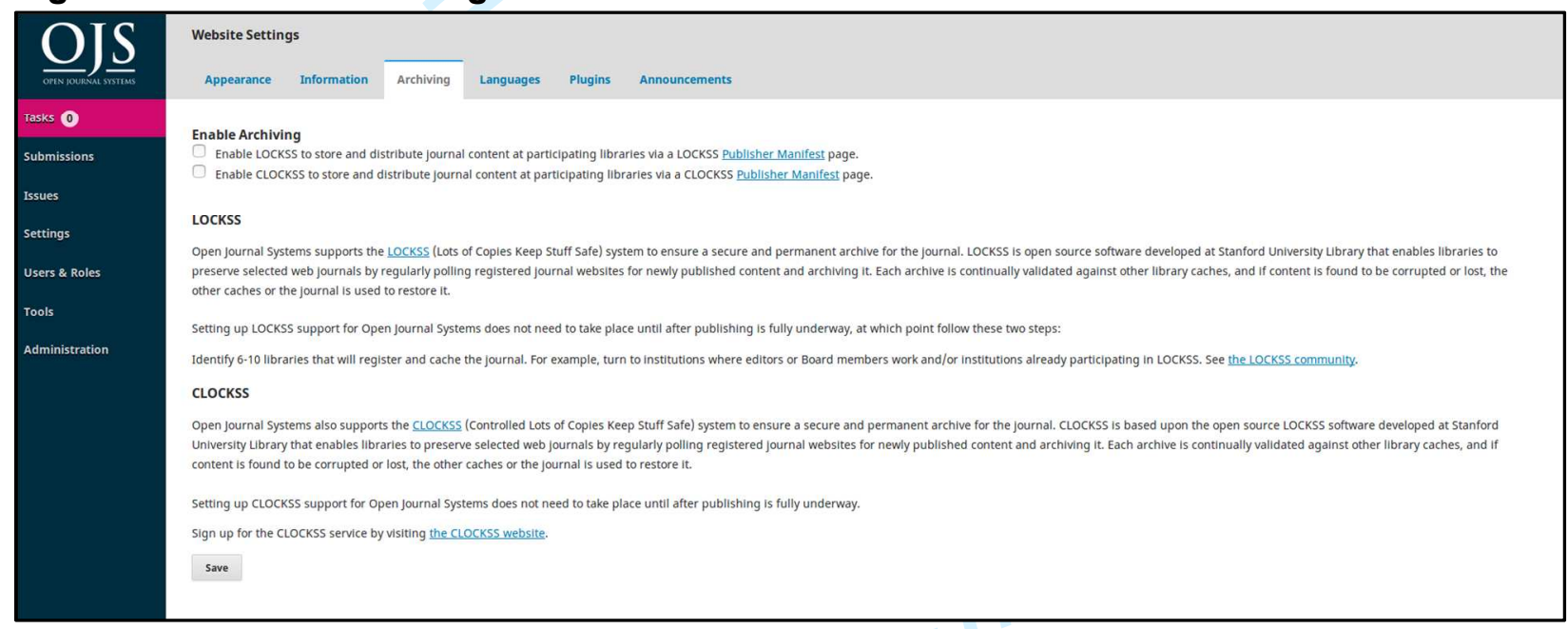

In OJS 3.1, the PKP PN plugin will be integrated with the other preservation plugins available in OJS: CLOCKSS, LOCKSS, and Portico ${ }^{14}$ (Figure 6). These other preservation options are hidden within an "Alternate Archiving Options" block that is collapsed by default. This approach should provide a usability improvement for the PKP PN as it serves to contextualize the PKP service as a preferred archiving option and as an administrative/website setting, and is much easier for journal managers to locate than in the previous version of OJS. Figure 6 depicts the Archiving tab after the user clicks on the link to expand it.

\section{Figure 6: OJS 3.1 Archiving tab}

\footnotetext{
${ }^{12}$ Based on the Global LOCKSS Network's titles database.

${ }^{13}$ PLNs other than PKP's preserve OJS titles; for example, the Council of Prairie and Pacific University Libraries (COPPUL) PLN preserves approximately 50 titles. However, these do not account for the number of OJS journals that have enabled LOCKSS.

${ }^{14}$ The text relating to the Portico plugin was not finalized for the Archiving tab at time of screenshot.
} 


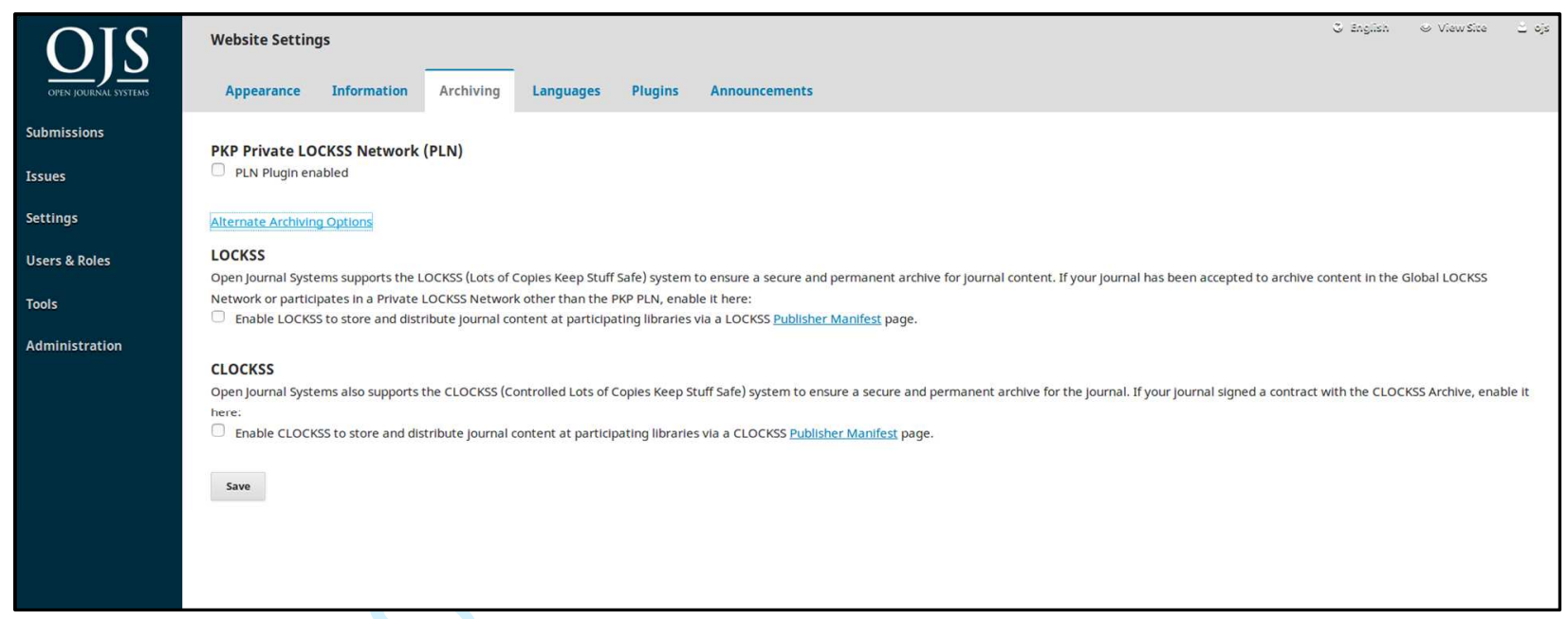

\section{Refining the Network's Infrastructure}

Around a year and a half after the launch of the PKP PN, its technical and infrastructural components have proven to be stable and reliable. In a small number of cases, the PN encounters issues with registering journals and with harvesting deposits. The two most common causes of these issues are nonstandard configuration of the web server that the journal is hosted on, and variations in the operating environment of the journal. PKP is improving the PKP $P N$ plugin's ability to detect these variations in a journal's server environment and to report them to the journal manager.

Several other areas of development are on PKPs roadmap for the PN:

- Harvesting and preservation of supplemental files: OJS allows authors to publish raw data files, videos, and other "supplemental files" with articles. Currently, the PKP PN only preserves the article text (PDF and/or HTML and embedded images); it does not preserve supplemental files. Work is underway to address this functionality.

- Automatic resolution of article DOls (Digital Object Identifiers) to the access node: Many articles published in OJS have DOIs ${ }^{15}$. It should be possible to update the DOIs for articles that have them to point to triggered content.

- Feedback to the journal manager or editor about actions they can take to facilitate the preservation of their content: Currently, the only feedback that journal managers get about their journal's content is the status of each deposit's progress through the deposit/harvest/storage workflow. Since the staging server runs validity checks on the harvested content, it should be possible for it to send information back to the journal manager or editor that may help them change local policies and practices to enhance the preservability of their content. One example of this type of information is the choice of preservation-friendly file formats for supplemental files.

- Automated tools for extracting content from the PN and ingesting it into the access node: Ideally, the process of making a triggered journal accessible again should be as

${ }^{15}$ https://pkp.sfu.ca/crossref/ 
automated as possible. Tools for doing this will leverage OJS's ability to import journal content.

\section{Understanding Our Users Better}

A significant obstacle to developing these new features is that PKP does not have a formal business relationship with the journals preserved in the network, or with journals that wish to be preserved but are not for some reason (e.g., the journal manager does not have the authority to accept the terms of service). This lack of relationship results in incomplete knowledge about the journals' requirements and awareness of preservation issues on the part of PKP. In other words, since PKP cannot communicate with the managers and editors of the journals it is serving (or could potentially serve) with the $\mathrm{PN}$, its ability to improve this service is hindered.

The large number of journals that may qualify for inclusion in the $\mathrm{PN}$, and their broad diversity in terms of staffing resources, make formal relationships and effective communication between potential and current clients of the PN and PKP (which also has limited staff to devote to this level of communication) challenging. This lack of relationships is not necessarily negative. PKP has never required that anyone register or self-identify before downloading its software, and central to PKP's philosophy is that anyone, anywhere, can download OJS and use it to publish a journal: "Researchers from all over the world can download and use our software; in a very real sense, journals from Indonesia and Sri Lanka can operate on the same field (or quality of platform) as journals from the United States and Germany" (MacGregor, Stranack, and Willinsky 2014, 172). John Willinsky, founder of PKP elaborates:

$[T]$ he original thinking behind the distributed model was to develop local capacities able to support this and other OSS [open source software] systems and tools with some autonomy and ownership, against a legacy of knowledge centers and peripheries, while we took on the additional responsibilities of providing a selfinstructive system by which others could find their way (Willinsky, personal message to author, Oct 29, 2017).

Recently, PKP has added an opt-out feature to OJS that does send a minimal set of publicly available data back to PKP (Alperin, Stranack and Garnett 2016, 60), which will help PKP improve its software and services while allowing OJS journals to remain autonomous and anonymous.

In addition to improvements to the OJS interface to make the PKP PN plugin easier to find and to provide contextual information about the different preservation options within OJS, defining a communication strategy will be key to increasing the number of OJS journals that are preserved in the PN. Although promotion of the service has not been a major focus thus far, once the PKP PN plugin is available in OJS 3.1, increased promotional efforts to OJS journals and their institutional hosts will be timely. Determining a communication strategy is complicated, however, both because there is no easy method of contacting journals or hosts, and because of a likely lack of awareness of preservation issues on the part of the journal publisher (for example, a 
question about the difference between back-ups and preservation has already arisen in relation to the PKP PN). In requiring that the journal manager accept the terms of service, the PKP PN shifts the onus for preserving journal content from libraries and librarians to journal publishers. Whereas library hosts can be expected to be somewhat familiar with preservation issues, small journal publishers will not be as aware.

As part of their Strategies for Expanding EJournal Preservation Mellon-funded project, Cornell contacted over 350 small publishers, most of whom - much like OJS publishers - publish only one or two titles, in regards to their participation in a potential preservation project. Their key takeaway from this exercise was "not that publishers are resistant to preservation because of costs, or digital rights management concerns, but that there is a lack of understanding of digital preservation and its objectives" (Regan, 95). One of the central findings reached by the project holds great promise for the PKP PN and indeed, for other preservation efforts: "if we invest in efforts to educate publishers it will make great strides in expanding the preservation of ejournals.... [o]utreach and education have the potential to go a long way in securing scholarship" (Regan, 95).

\section{Conclusion}

PKP considers 600 journals preserved in the PKP PN within the first year and a half of operation to be a success. However, given that there are over 10,000 OJS journals (2,500 of which could be using it now, provided they can accept the terms of service) that could be taking advantage of the service begs the question of why that number is not higher. PKP purposefully collects little information about OJS users, making PN feature development and communication with potential users challenging. Nonetheless, considering that many more journals enable the LOCKSS plugin within OJS than are preserved in the Global LOCKSS Network or a Private LOCKSS Network, and that evidence from a variety of studies demonstrates that small publishers are interested in preservation, the authors anticipate that upcoming usability improvements in the OJS interface and a focus on promoting the benefits of inclusion in the PKP PN will greatly increase the number of journals that opt into the service.

From a more general perspective, the PKP PN demonstrates that it is possible to implement distributed digital preservation services that both preserve content from a large number of partners, and that require little direct interaction with those partners. Determining an effective amount of interaction with a service's users is probably best determined by understanding their needs and the amount of risk faced by their content but should also take into account the ability of all partners to manage that interaction.

\section{Works Cited}

Alperin, Juan Pablo, Kevin Stranack and Alex Garnett. 2016. "On the Peripheries of Scholarly Infrastructure: A Look at the Journals Using Open Journal Systems." 21st International 
Conference on Science and Technology Indicators, València (Spain), September 14-16, 2016. http://ocs.editorial.upv.es/index.php/STI2016/STI2016/paper/viewFile/4543/2327

Ayre, Catherine, and Adrienne Muir. 2004. "The Right to Preserve." D-Lib Magazine, vol. 10, no. 3, 03/01/2004, doi:10.1045/march2004-ayre

Beagrie, Neal. September 2013. "Preservation,Trust and Continuing Access for E-Journals." DPC Technology Watch Report, 13-04.

http://www.dpconline.org/docs/technology-watch-reports/924-dpctw13-04/file

Bjornshauge, Lars. 2014. "e-Journal Archiving: Changing Landscape." Presentation at the CNI Fall 2014 Fall Membership Meeting. https://www.cni.org/wp-content/uploads/2014/12/cni ejournal rieger.pdf

Burnhill, Peter. 2013. "Tales from The Keepers Registry: Serial Issues About Archiving \& the Web." Serials Review 39, 3-20.

https://www.era.lib.ed.ac.uk/bitstream/handle/1842/6682/Tales From The Keepers.pdf?seque $\underline{\text { nce }=1 \text { \&isAllowed }=y}$

Burnhill, Peter and Lisa Otty. 2015. "Is it too late to ensure continuity of access to the scholarly record?" 2015 IATUL Proceedings.

http://docs.lib.purdue.edu/cgi/viewcontent.cgi?article=2086\&context=iatul

Cornell University Library \& Columbia University Library. October 2011. "Final Report of the 2CUL LOCKSS Assessment Team."

http://www.2cul.org/sites/default/files/2CULLOCKSSFinalReport.pdf

Edgar, Brian D. and John Willinsky. 2010. "A Survey of Scholarly Journals Using Open Journal Systems." Scholarly and Research Communication, 1: 2.

http://src-online.ca/index.php/src/article/view/24

Kenney, Anne R. and Kathryn Wesley. 2016. "Building a Social Compact for Preserving EJournals." The Serials Librarian. 70:1-4, 72-84. 10.1080/0361526X.2016.1141630

MacGregor J., Stranack K., Willinsky J. 2014. "The Public Knowledge Project: Open Source Tools for Open Access to Scholarly Communication." In: Bartling S., Friesike S. (eds) Opening Science. Springer, Cham. https://doi.org/10.1007/978-3-319-00026-8 11

Marchitelli, Andrea, Paola Galimberti, Andrea Bollini, and Dominic Mitchell. 2017. "Helping Journals to Improve their Publishing Standards: A Data Analysis of DOAJ New Criteria Effects." JLIS. it 8 (1): 1.

Owen, Brian and Kevin Stranack. 2012. "The Public Knowledge Project and Open Journal Systems: open source options for small publishers." Learned Publishing, 25, 138-144. http://dx.doi.org/10.1087/20120208 
Regan, Shannon. 2016. "Strategies for Expanding E-Journal Preservation, The Serials Librarian.” The Serials Librarian, 70:1-4, 89-99.

http://dx.doi.org/10.1080/0361526X.2016.1144159

Reich, Victoria and David Rosenthal. 2009. "Distributed Digital Preservation: Private LOCKSS Networks as Business, Social, and Technical Frameworks." Library Trends, 57:3, 461-475. Project MUSE, doi:10.1353/lib.0.0047

Seadle, Michael. March, 2011. "Archiving in the networked world: by the numbers", Library HiTech, 29:1, 189-197.

Skinner, Katherine and Matt Schultz (Eds). 2010. A Guide to Distributed Digital Preservation. Educopia Institute.

https://educopia.org/sites/educopia.org/files/publications/A Guide to Distributed Digital Preser vation 0.pdf 


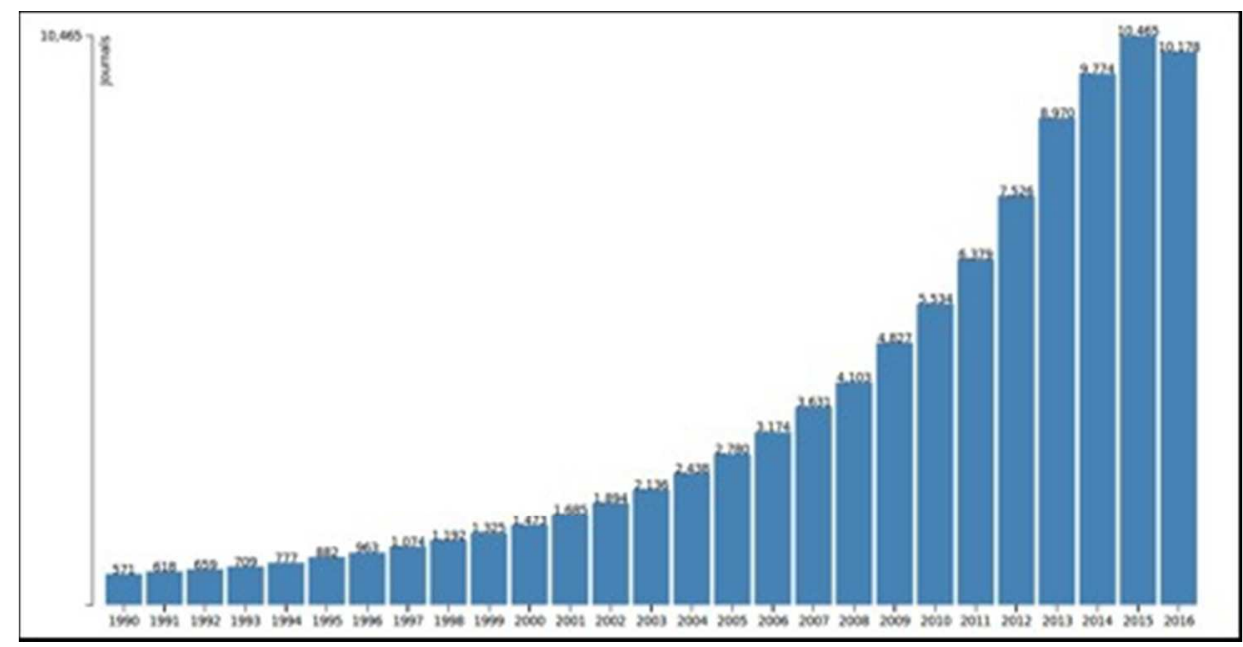

OJS usage over time

$165 \times 85 \mathrm{~mm}(72 \times 72$ DPI $)$ 


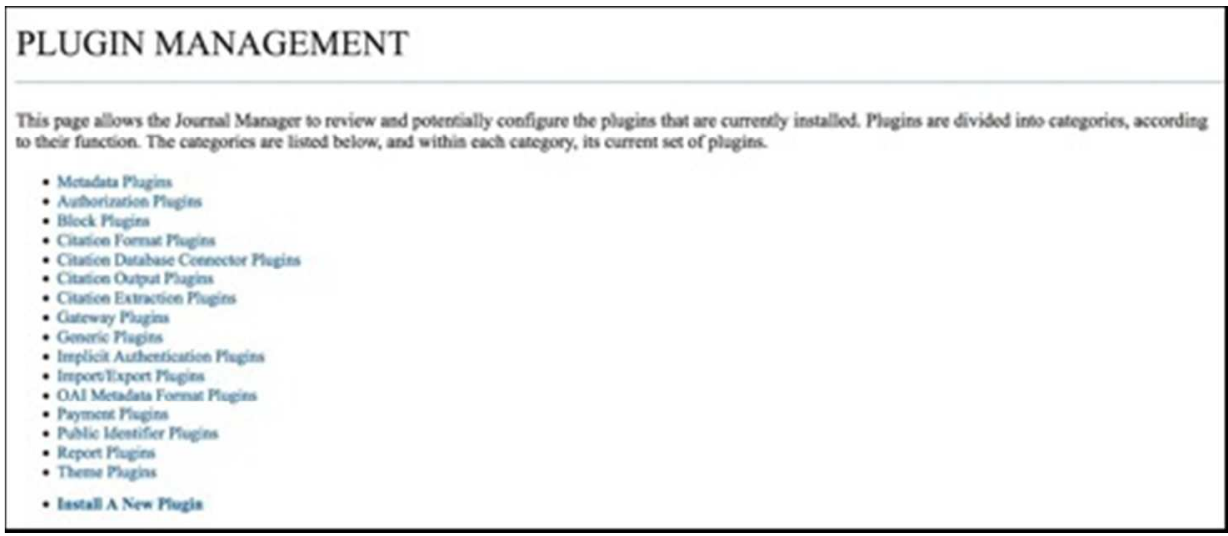

OJS 2.4.8 Plugin Management $165 \times 71 \mathrm{~mm}(72 \times 72 \mathrm{DPI})$ 


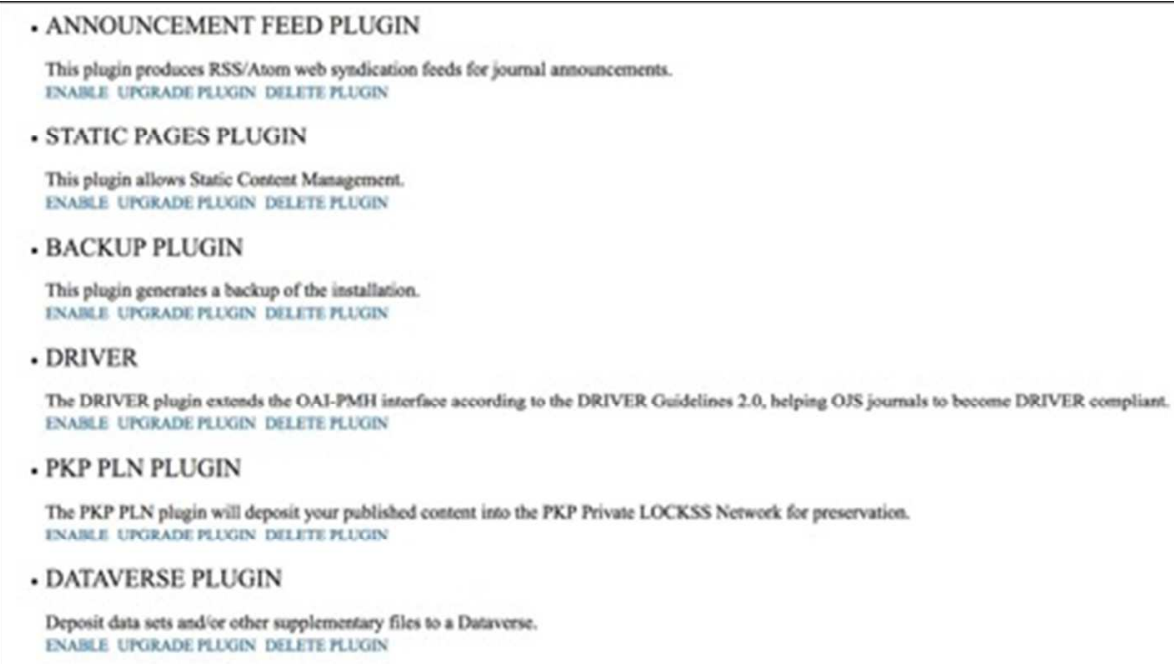

OJS 2.4.8 Generic Plugins (partial list) $165 \times 91 \mathrm{~mm}(72 \times 72 \mathrm{DPI})$ 


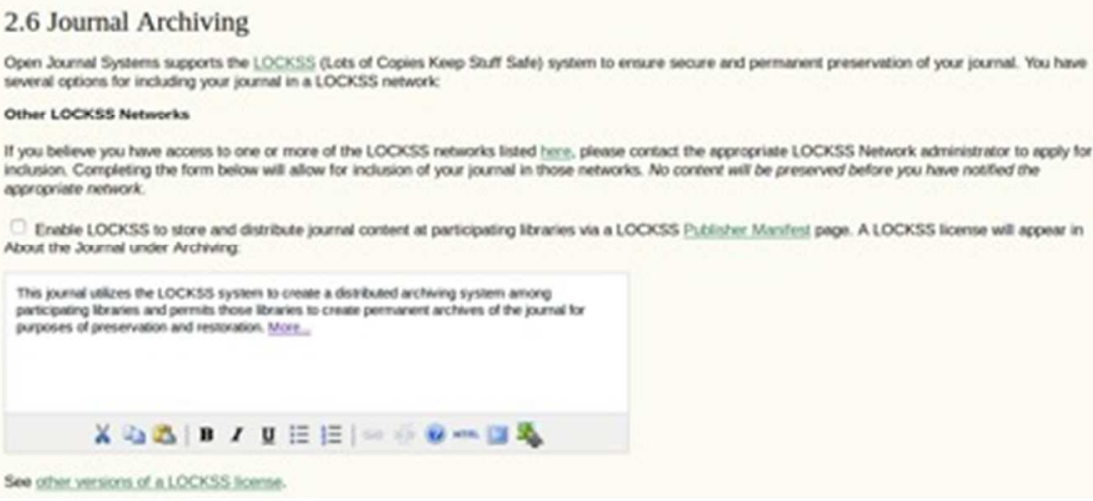

OJS 2.4.8 Journal Archiving options

$165 \times 70 \mathrm{~mm}(72 \times 72 \mathrm{DPI})$ 


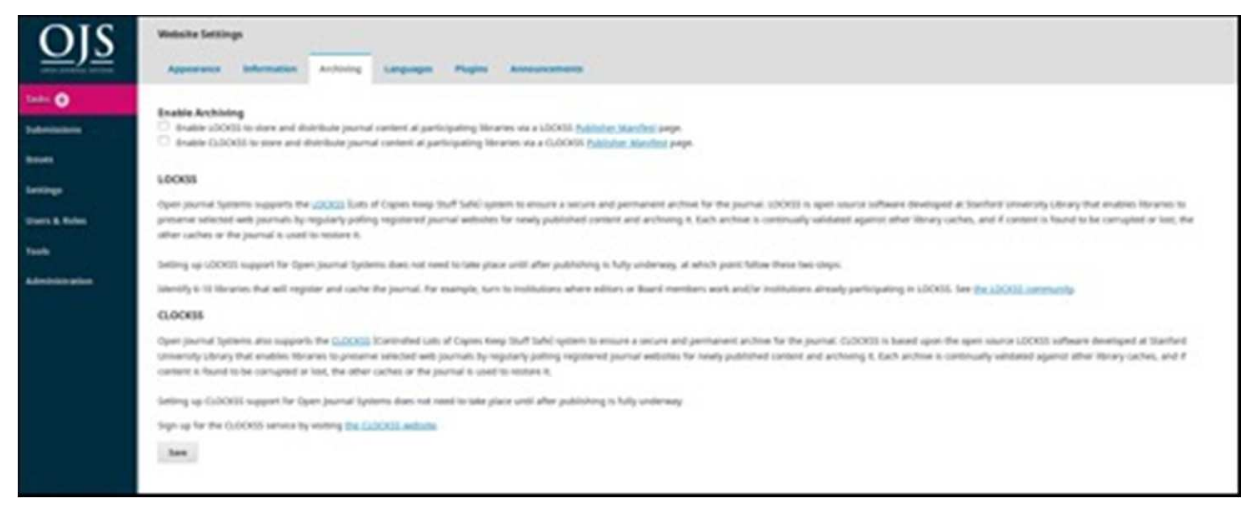

OJS 3.0 Archiving tab

$165 \times 65 \mathrm{~mm}(72 \times 72$ DPI $)$ 


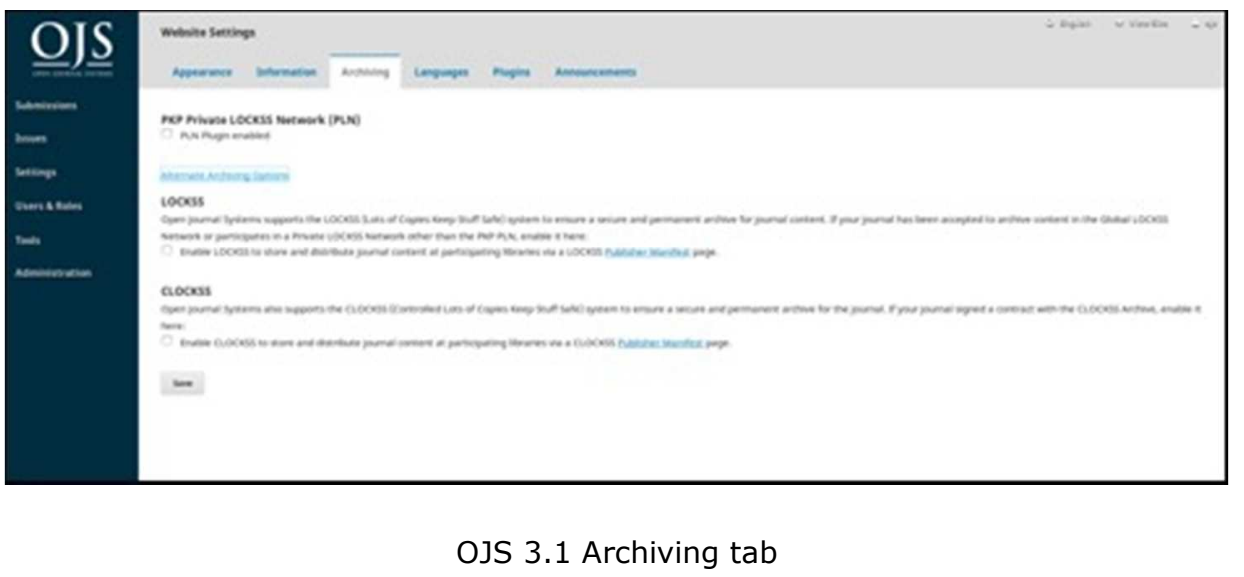

$165 \times 64 \mathrm{~mm}(72 \times 72$ DPI $)$ 